\title{
Shaping Ability of Twisted File, HERO Shaper and Profile .06 Ni-Ti Instruments in Simulated Curved Root Canals \\ Love RM* and Masi OV
}

Department of Oral Rehabilitation, University of Otago School of Dentistry, PO Box 647, Dunedin, New Zealand

\section{Abstract}

Aim: To determine the shaping and centering ability of Twisted File (TF), HERO Shaper file and the ProFile .06 in simulated curved root canals.

Methodology: Sixty simulated root canals of either $20^{\circ}, 10 \mathrm{~mm}$ radius $(n=30)$ or $30^{\circ}, 6 \mathrm{~mm}$ radius $(n=30)$ canal curvatures were prepared with three file systems in a variable tip, modified Crown Down technique. Mean changes on the inner and outer canal walls were analysed for shaping and centering ability of the systems and analysed using ANOVA.

Result: There were no significant differences in canal preparations between the $20^{\circ}$ and $30^{\circ}$ canal curvatures with each system $(p>0.05)$. All file systems produced well-tapered canal preparations. Overall HERO shaper removed the least canal wall material $(p<0.05)$, while the other two systems were comparable $(p>0.05)$. TF showed a better ability to remove inner canal wall material and remain centered in the apical third $(p<0.05)$, while Profile and HERO transported to the outer wall.

Conclusion: All systems produced clinically acceptable canal shapes. TF files showed a better ability to instrument the inner canal wall and remain centered in the apical region. HERO Shaper file was observed to remove the least material in all regions.

Keywords: Curved root canal; Twisted file; HERO shaper file

\section{Introduction}

Chemo-mechanical preparation in shaping, cleaning and disinfecting the root canal system is said to be the most important phase in endodontic treatment. Eradication of microbial infection is the primary objective of this treatment phase, though shaping the canal to a funnel shape from the coronal to apical end facilitates filling of the canal to achieve an optimum seal from tissue fluid [1].

There are a number of techniques and instruments that can be used to mechanically prepare root canals and the choice of a particular system can pose a dilemma to a clinician. The introduction of nickeltitanium alloy (Nitinol, NiTi) [2] with its high strength, low modulus of elasticity and unique properties of shape memory and super-elasticity paved the way for an advance in instrument design to facilitate shaping and cleaning canals with the high flexibility providing the potential to better negotiate curved canals compared with more rigid stainless steel files. There is consensus that $\mathrm{Ni}$ - $\mathrm{Ti}$ instrumentation systems can produce well-centred and flared root canal preparations [3-5]. Having a wide selection of $\mathrm{Ni}$-Ti file systems to select from requires a clinician to understand the physical properties, design characteristics, and motion mechanics within the confines of the canal system before using a particular system.

The Twisted file (TF) (SybronEndo, Dental Specialties, Orange, CA) was recently introduced with the manufacturer claiming it possesses high flexibility. The flute design of this Ni-Ti file system is formed by twisting rather than grinding the material. Twisting occurs at a specific temperature range (R-phase technology) and helps prevent crack propagation and subsequently increases fatigue strength and gives the file inherent superelastic flexibility [6]. A triangular cross-section, variable pitch to alleviate the pull-in effect, and a non-cutting tip are incorporated in its design.

This study examined the shaping and centering ability of Twisted File (TF) to the more established HERO Shaper and the Pro-File .06 file systems, in mechanical instrumentation of pre-flared $20^{\circ}$ and $30^{\circ}$ simulated curved root canals in plastic blocks to a master apical size 40. The taper of the preparation was dependent on the manufacturer's instrumentation and sequencing.

\section{Materials and Methods}

Sixty transparent plastic blocks (TRIMUNT Corporation, Nissin Dental Products, Kyoto, Japan) with an encased and colored, simulated $20 \% 10 \mathrm{~mm}$ radius or $30 \% \mathrm{~mm}$ radius curved root canal were randomly assigned to groups to be prepared using one of three file systems: Twisted file (SybronEndo, Orange, CA, USA) $\left(20^{\circ}, \mathrm{n}=10 ; 30^{\circ}, \mathrm{n}=10\right)$ HERO Shaper (Micro-mega, Besancon, France) $\left(20^{\circ}, \mathrm{n}=10 ; 30^{\circ}, \mathrm{n}=10\right)$, or Profile .06 (Dentsply, Maillefer, Switzerland) $\left(20^{\circ}, \mathrm{n}=10 ; 30^{\circ}, \mathrm{n}=10\right)$.

\section{Imaging of simulated root canals}

Images of all the simulated root canals prior to and after preparation were captured as follows. Each plastic block was labeled for ease of referencing and three orientation holes were prepared on the vertical face, with a diamond bur. These orientation holes were used as guides, to correct the superimposition of digital images using Adobe Photoshop (CS4 Extended). The imaging site (block positioning site) was marked to identify a reproducible and consistent position for a plastic block. The site was positioned on a stable surface to facilitate a contrasting, flat background. A stainless steel endodontic ruler was positioned alongside the image site, as a measuring aid for the images. The orientation of the

*Corresponding author: Professor Robert M. Love, Department of Ora Rehabilitation, University of Otago School of Dentistry, PO Box 647, Dunedin, New Zealand, Tel: 643 4797121; Fax: 643 4797046; E-mail: robert.love@otago.ac.nz

Received September 27, 2013; Accepted November 25, 2013; Published November 27, 2013

Citation: Love RM, Masi OV (2013) Shaping Ability of Twisted File, HERO Shape and Profile $.06 \mathrm{Ni}-\mathrm{Ti}$ Instruments in Simulated Curved Root Canals. Dentistry 3 171. doi:10.4172/2161-1122.1000171

Copyright: $\odot 2013$ Love RM, et al. This is an open-access article distributed under the terms of the Creative Commons Attribution License, which permits unrestricted use, distribution, and reproduction in any medium, provided the original author and source are credited. 
block site was centered through the camera lens (Canon EOS 450D (EF$\mathrm{S} 18-55 \mathrm{~mm} \mathrm{f} / 3.5-5.6$ IS lens) after focal adjustment. All images were captured at a standard lens to image distance (focal distance) of $12 \mathrm{~cm}$. A mini fluorescent head-lamp was positioned $10 \mathrm{~cm}$ away from the site, the light emitted was directed towards the plastic block and corrected for optimum lighting to fall on the block. Extra lighting was provided by the camera flash and camera adjustments were made to produce a clear and contrasting final image. Images were then downloaded into a PC (Acer, Extensa 5620Z, China) and stored in an EOS Utility pictures folder.

Initial calibration and adjustments were conducted to set a standard scale of 63 pixels $=1000 \mu \mathrm{m}$ on Adobe Photoshop CS4 (Adobe Systems Inc., San Jose, CA, USA) for all digital images of pre-preparation and after-preparation canals. The magnification was set at $200 \mathrm{x}$ on PS Workspace.

\section{Preparation of simulated canals}

To confirm canal patency a size $10 \mathrm{~K}$ file was initially inserted into the simulated canal. Orifice Shapers (Dentsply, Maillefer, Switzerland) \#4, \#5 and Endo-flare (Micro-mega, Besancon, France) 25, .12 files were then tested on each canal to verify flaring at the coronal third.

A variable tip, modified Crown-Down preparation technique was used for all canal preparations. The file systems were used according to the manufacturers' recommendations and modified to standardize the apical preparation to size 40 , approximately 3 file sizes greater than the apical diameter (Table 1).

A TC-motor 3000 (NOUVAG, Goldach, Switzerland) high torque electric motor (set torque, $315 \mathrm{rpm}$ ) with a 16:1 reduction contra-angle handpiece (Dentsply, Maillefer, Switzerland) was used with each file to prepare the canals. The working length was measures at $0.5 \mathrm{~mm}$ short of the canal terminus.

In all cases the canals were flushed with copious water irrigation before preparation and after each single file use, using a $10 \mathrm{ml}$ Luer-Lok syringe fitted with a 27 gauge Monoject needle. Lubricant was not used as it may have masked the canal margins and caused discrepancies in

\begin{tabular}{|c|c|c|c|c|c|}
\hline File system & & & & & Apical size \\
\hline Twisted Files & $35 / .06$ & $30 / .06$ & $25 / .06$ & $25 / .08$ & $40 / .04$ \\
\hline Hero Shaper & $40 / .06$ & $35 / .04$ & $25 / .04$ & $30 / .04$ & $40 / .06$ \\
\hline ProFile & $40 / .06$ & $35 / .06$ & $30 / .06$ & $25 / .06$ & $40 / .06$ \\
\hline
\end{tabular}

Table 1: Simulated canal preparation sequence by file size/file taper (\%).

\begin{tabular}{|c|c|c|c|}
\hline & Twisted file & ProFile & HERO Shaper \\
\hline Coronal & $47.0 \pm 27.32$ & $43.4 \pm 27.79$ & $15.4 \pm 13.19$ \\
\hline Middle & $92.8 \pm 37.91$ & $109.0 \pm 22.28$ & $35.1 \pm 18.74$ \\
\hline Apical & $135.7 \pm 39.5$ & $117.6 \pm 31.75$ & $93.7 \pm 35.34$ \\
\hline MEAN & $94.5 \pm 27.98$ & $92.8 \pm 17.94$ & $50.0 \pm 18.33$ \\
\hline
\end{tabular}

Table 2: Mean amount $(\mu \mathrm{m})$ of canal wall material removed across measurement regions.

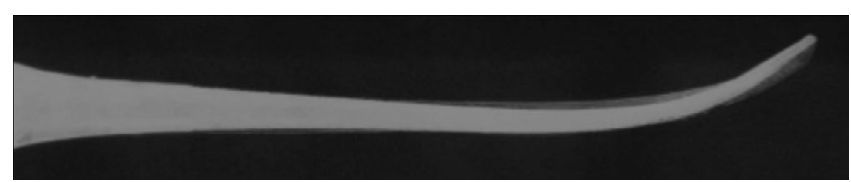

Figure 1: Representative image of a simulated root canal prepared using ProFile instruments. Note preferential removal of inner-wall material at the midroot area and outer-wall in the apical area. measurement. Size 25 paper points were used to dry each canal, before taking after-preparation images.

\section{Analysis of canal dimension}

To measure the amount of canal wall removed each pair of prepreparation and preparation images were super-imposed on Photoshop CS4, then using the pen tool a line was scribed centrally along the long axis of the canal. Measurements were taken perpendicular from this central axis to the inner and outer canal wall at each millimeter interval, commencing at $0.5 \mathrm{~mm}$ from the apical stop, to end at $19 \mathrm{~mm}$ in the coronal third. Measurements were recorded in micrometers $(\mu \mathrm{m})$ and were automatically delivered and stored in the measurement log. The collated data and images were then saved in a file and exported to a Microsoft Excel (Microsoft, Windows 2007) spreadsheet. Data from the apical, middle, or coronal regions were grouped for analysis.

The formula used for determining the centering ability of each file was: $\sigma \Delta \mathrm{x}$ (mean change across outer canal wall measurements) - $\sigma \Delta \mathrm{y}$ (mean change across inner canal wall measurements) = transportation/ deviation on outer or inner wall. A negative value represented transportation of the prepared canal to the inner wall; a positive value represented transportation to the outer wall, while a zero reading represented perfect centering.

Analysis was completed using SPSS (PASW 18). Raw data were sorted with an acceptable structure in Microsoft Excel then exported for statistical analysis using the Analysis of variance (ANOVA) test.

\section{Results}

The dimensions of the simulated canals were evaluated from the pre-operative images. The average length was $20 \mathrm{~mm}$ from the orifice to the canal termination, the diameter of the canal at the canal termination was $0.26 \pm 0.04 \mathrm{~mm}$ and the canal flared to the orifice with a diameter of $2.58 \pm 0.14 \mathrm{~mm}$. The radius of curvature was approximately 10.0 $\mathrm{mm}$ for the $20^{\circ}$ canal and $6.0 \mathrm{~mm}$ for the $30^{\circ}$ canals. The curvature of the canal commenced at approximately $12 \mathrm{~mm}$ from the orifice for $20^{\circ}$ canals and $13 \mathrm{~mm}$ for $30^{\circ}$ canals.

\section{Overall removal of canal wall material}

The mean material removed from all measurement sites showed that overall Hero Shaper removed significantly less canal wall material that Twisted file or ProFile $(\mathrm{p}<0.05)$ while there was no difference ( $p>0.05$ ) between Twisted File or ProFile (Table 2 and Figure 1). When comparing the mean amount of canal wall material removed between the $20^{\circ}, 10 \mathrm{~mm}$ radius and $30^{\circ}, 6 \mathrm{~mm}$ radius canal curvatures $(81.4 \pm$ $31.07 \mu \mathrm{m}$ and $76.7 \pm 29.07 \mu \mathrm{m}$ respectively) there was no difference for any file system $(\mathrm{p}>0.05)$.

In the apical, middle or coronal third of the canal HERO Shaper removed the least material compared to Twisted file and Profile $(\mathrm{p}<0.05)$ (Table 2), while there was no difference $(\mathrm{p}>0.05)$ in material removed between Twisted file and Profile across any group.

The mean changes across each third of the simulated root canal, clearly show that each of the three files removed less material in the coronal region and more in the apical region $(\mathrm{p}<0.05)$. This was indicative that the canals were pre-flared.

\section{Removal of inner and outer canal wall material}

The mean changes across all the measurement sites for each file are presented in Table 3 and show that Twisted files removed the most material from the inner canal wall and HERO Shaper the least $(\mathrm{p}<0.05)$. 


\begin{tabular}{|l|c|c|c|c|}
\hline & HERO Shaper & Profile 0.06 & Twisted file & Overall mean \\
\hline Inner canal wall & $38.3 \pm 15.67$ & $80.7 \pm 23.59$ & $108.7 \pm 43.17$ & $75.9 \pm 41.32$ \\
\hline Outer canal wall & $61.6 \pm 29.56$ & $104.8 \pm 26.04$ & $80.3 \pm 25.67$ & $82.2 \pm 32.09$ \\
\hline
\end{tabular}

Table 3: Mean changes $(\mu \mathrm{m})$ across inner and outer measurement sites.

\begin{tabular}{|l|c|c|c|}
\hline & $\mathbf{3 0}^{\circ}$ & $\mathbf{2 0}^{\circ}$ & Overall mean \\
\hline Inner canal wall & $76.2 \pm 38.35$ & $75.7 \pm 4476$ & $75.9 \pm 41.32$ \\
\hline Outer canal wall & $77.3 \pm 31.67$ & $87.2 \pm 32.27$ & $82.2 \pm 32.09$ \\
\hline
\end{tabular}

Table 4: Mean changes $(\mu \mathrm{m})$ across inner or outer walls by canal curvature.

\begin{tabular}{|c|c|c|c|}
\hline & HERO Shaper & Profile & Twisted file \\
\hline Apical region & & & \\
\hline Inner canal wall & $58.4 \pm 14.43$ & $80.7 \pm 29.64$ & $132.8 \pm 50.16$ \\
\hline Outer canal wall & $128.9 \pm 62.98$ & $154.5 \pm 48.85$ & $138.7 \pm 42.39$ \\
\hline Middle region & & & \\
\hline Inner canal wall & $39.0 \pm 27.21$ & $107.2 \pm 31.29$ & $138.5 \pm 63.97$ \\
\hline Outer canal wall & $31.2 \pm 26.11$ & $110.9 \pm 40.56$ & $47.2 \pm 30.15$ \\
\hline Coronal region & & & \\
\hline Inner canal wall & $13.5 \pm 14.14$ & $49.0 \pm 31.44$ & $44.1 \pm 47.35$ \\
\hline Outer canal wall & $17.3 \pm 21.73$ & $37.8 \pm 42.53$ & $50.0 \pm 36.62$ \\
\hline
\end{tabular}

Table 5: Mean changes $(\mu \mathrm{m})$ across inner and outer canal wall measurement sites by region.

\begin{tabular}{|c|c|c|c|}
\hline & HERO Shaper & Profile & Twisted file \\
\hline Apical region & 70.56 & 73.79 & 5.85 \\
\hline Middle region & -7.88 & 3.65 & -91.23 \\
\hline Coronal region & 3.82 & -11.20 & 5.96 \\
\hline
\end{tabular}

Table 6: Centering ability of instruments $(\sigma \Delta x-\sigma \Delta y)$ by region. Positive value indicates transportation to the outer wall; negative value indicates transportation to the inner wall; zero value indicates perfectly centered preparation.

For the outer canal wall measurement sites Profile removed the most material and HERO Shaper the least $(\mathrm{p}<0.05)$. Twisted files removed more material from the inner canal wall than Profile $(\mathrm{p}<0.05)$, while ProFile removed more from the outer wall than Twisted file $(\mathrm{p}<0.05)$.

There was no significant difference in the mean changes for the outer or inner canal walls between the two canal curvatures $(p>0.05)$ (Table 4).

\section{Mean changes in the apical third region}

Twisted file removed the most material from the inner wall, followed by Profile with HERO Shaper removing the least material $(p<0.05)$ (Table 5). There were no significant differences $(p>0.05)$ in the amount of material removed (Table 5 ) from the outer canal wall between the three files.

\section{Mean changes in the middle third region}

Twisted file removed the most material from the inner wall and HERO Shaper the least $(p<0.05)$ (Table 5). On the outer wall Profile removed significantly $(\mathrm{p}<0.05)$ more material than Twisted file or HERO Shaper files, there were no other significant differences.

\section{Mean changes in the coronal third region}

The mean change across all measurement sites (Table 5) showed that HERO Shaper removed significantly $(\mathrm{p}<0.05)$ less material than Profile or Twisted files on the inner canal wall and less than Twisted files on the outer canal wall. There were no other significant differences.

\section{Centering of the canal preparations}

In the apical region of canals prepared with the Twisted file the canals were evenly centered while those prepared with Profile or HERO Shaper were transported towards the outer wall (Table 6). In the middle region Profile and HERO Shaper produced evenly centered preparations while Twisted file transported the canal to the inner wall. In the coronal third the preparation by all the file systems were centered (Table 6).

\section{Discussion}

The use of simulated root canals in plastic blocks does not fully reflect the clinical application of endodontic files however it is a useful method for evaluating the canal shape that a system can prepare. Canal preparation was conducted in simulated canals of moderate $\left(20^{\circ}\right)$ or severe $\left(30^{\circ}\right)$ canal curvature, the latter having a smaller radius and greater curvature. The curvature and radius of a canal may present difficulty in shaping the apical third and can result in transportation on the outer canal wall resulting in zipping or ledge formation or underpreparation of the inner wall resulting in incomplete debridement and removal of microbial biofilm [7]. Despite this, and that the file systems use different taper sequences, each file system that was tested prepared the two canal curvatures comparably well with no significant difference in overall root canal wall material removed between the canals. This indicates that the file systems are able to manage differing degrees of curvature, contributing to this ability is a combination of the sequential crown-down technique, file flexibility, and design features such as flute shape and a non-cutting tip that guides files along the canal wall.

The cleaning ability of an endodontic file can, in part, be determined on the amount or depth of canal wall removed. A Profile .06 preparation sequence was used as a recognised standard as it has been extensively researched showing that it produces a well tapered preparation but with a tendency to transport to the outer wall apically with minimal debridement of the inner canal wall [7-10]. The amount of material removed by canal region showed differences within a file system and between files. In all regions HERO Shaper significantly removed the least material compared to TF and Profile .06. The few studies investigating HERO Shaper files concluded that they shaped and performed well in root canal preparation. The predecessor to this file HERO 642 was found to prepare canals with a poor taper $[11,12]$ which was suggested reflected the lack of penetration of a greater taper instrument with a helical flute angle that was designed to reduce the screwing in effect but conversely removed less material from the canal wall. This may also account for the HERO Shaper producing the least mean changes in all regions as the helix angle on the cutting edge increases to prevent binding. Another possible reason for the amount of material removed may be that the HERO Shaper sequence used $4 \%$ tapered files in preparing the bulk of the canal (Table 1) compared to $6 \%$ tapered files in the other systems. HERO 642 studies observed transportation was towards the outer aspect of the curve except at the orifice and the authors concluded that the tendency may be due to the transition angle at the tip, rigidity of instruments of greater taper or the modified sequence of preparation $[13,14]$. In this study the same transportation pattern to the outer wall at the apical region while being more centered at the mid and coronal region was observed.

The flexibility of the prototype Twisted file was tested and compared to Profile .06 taper files in a standardized experimental model. The bending moments were measured and permanent deformation angles recorded. The findings revealed significantly higher flexibility in TF files, as compared to Profile .06 files. Additionally, Larsen et al. investigated the resistance to cyclic fatigue of TF files and comparisons were made to ground Ni-Ti rotary instruments [15]. A size $25 \mathrm{TF}$ file was significantly more resistant to cyclic fatigue than other files 
Citation: Love RM, Masi OV (2013) Shaping Ability of Twisted File, HERO Shaper and Profile .06 Ni-Ti Instruments in Simulated Curved Root Canals. Dentistry 3: 171. doi:10.4172/2161-1122.1000171

tested, except Profile \#25 .06. These properties are important to allow enlargement of the canal space with greater taper instruments while maintaining centering, especially at the apical region where the inner walls are commonly left un-instrumented. Gergi et al. compared the canal transportation and centering ability of TF files, Pathfile-Protaper and a stainless steel hand K-file [16]. Canals were assessed with crosssectional CT scan images. The findings showed the TF file significantly transported the least with the smallest mean degree of transportation and highest mean centering ratio in all regions compared to the other tested files. The results of the present study are in general agreement with this as TF produced more even removal of the canal wall in the apical third with less transportation and better centering than the other files. Of importance was the observation that TF was able to instrument the inner wall of the apical segment, an area commonly missed by other systems? This may be due to the design characteristics of the files but probably also reflects that the sequence uses an $8 \%$ tapered file prior to final apical preparation at a less taper (4\%) than the other tested files. Overall TF showed the greatest capacity to instrument the inner wall in the apical and middle thirds; however in the middle third this was reflected as transportation (Table 6) towards the danger zone for stripperforation [17]. Clinicians may need to consider this for an individual case.

\section{Conclusion}

The three Ni-Ti files tested have design features and inherent physical properties that offer a favourable shaping and cleaning ability. The TF showed the best centering at the apical region and the ability to debride the inner canal wall. HERO Shaper with its minimal debridement characteristic may be more effective when used in narrow canals. Within the limitation of this study all the tested files prepared well-shaped canals with minimal transportation.

\section{References}

1. Schilder H (1974) Cleaning and shaping the root canal. Dent Clin North Am 18: 269-296.

2. Buehler WH, Gilfrich JV, Wiley RC (1963) Effect of low temperature phase changes on the mechanical properties of alloys near composition $\mathrm{Ni}-\mathrm{Ti}$. Journal of Applied Physics 34: 1475-1477.

3. Guskin A, Brown D, Buchanan L (2001) A reconstructed computerized tomographic comparison of $\mathrm{Ni}$ - Ti rotary GT files versus traditional instruments in canals shaped by novice operators. Int Endod J 34: 476-484.
4. Schafer E, Florek H (2003) Efficiency of rotary nickel-titanium K3 instruments compared with stainless steel hand K-Flexofile. Part 1. Shaping ability in simulated curved canals. Int Endod J 36: 199-207.

5. Schafer E, Schlingemann R (2003) Efficiency of rotary nickel-titanium K3 instruments compared with stainless steel hand K-Flexofile. Part 2. Cleaning effectiveness and shaping ability in severely curved root canals of extracted teeth. Int Endod J 36: 208-217.

6. Kuhn G, Jordan L (2002) Fatigue and mechanical properties of nickel-titanium endodontic instruments. J Endod 28: 716-720.

7. Ayar LR, Love RM (2004) Shaping ability of Profile and K3 rotary Ni-Ti instruments when used in a variable tip sequence in simulated curved root canals. Int Endod J 37: 593-601.

8. Bryant ST, Thompson SA, Al-Omari MAO, Dummer PMH (1998a) Shaping ability of Profile rotary nickel-titanium instruments with ISO sized tips in simulated root canals: Part 1. Int Endod J 31: 275-281.

9. Bryant ST, Thompson SA, Al-Omari MAO, Dummer PMH (1998b) Shaping ability of Profile rotary nickel-titanium instruments with ISO sized tips in simulated root canals: Part 2. Int Endod J 31: 282-289.

10. Bryant ST, Dummer PM, Pitoni C, Bourba M, Moghal S (1999) Shaping ability of .04 and .06 taper ProFile rotary nickel-titanium instruments in simulated root canals. Int Endod J 32: 155-164.

11. Thompson SA, Dummer PM (1997) Shaping ability of ProFile .04 taper series 29 rotary nickel-titanium instruments in simulated root canals: Part 1. Int Endod J 30: 1-7.

12. Thompson SA, Dummer PM (1997) Shaping ability of ProFile .04 taper series 29 rotary nickel-titanium instruments in simulated root canals. Part 2. Int Endod J 30: 8-15.

13. Thompson SA, Dummer PMH (2000) Shaping ability of HERO 642 rotary nickel-titanium instruments in simulated root canals: Part 1. Int Endod $\mathrm{J} 33$ : 248-254.

14. Thompson SA, Dummer PMH (2000) Shaping ability of HERO 642 rotary nickel-titanium instruments in simulated root canals: Part 2. Int Endod J 33: 255-261.

15. Larsen CM, Watanabe I, Glickman GN, He J (2009) Cyclic fatigue analysis of a new generation of nickel-titanium rotary instruments. J Endod 35: 401-403.

16. Gergi R, Rjeily JA, Sader J, Naaman A (2010) Comparison of canal transportation and centering ability of Twisted files, Pathfile-ProTaper system and stainless steel hand K-files by using computed tomography. J Endod 36: 904-907.

17. Abou-Rass M, Frank AL, Glick DH (1980) The anti-curvature filing method to prepare the curved root canal. J Am Dent Assoc 101: 792-794. 